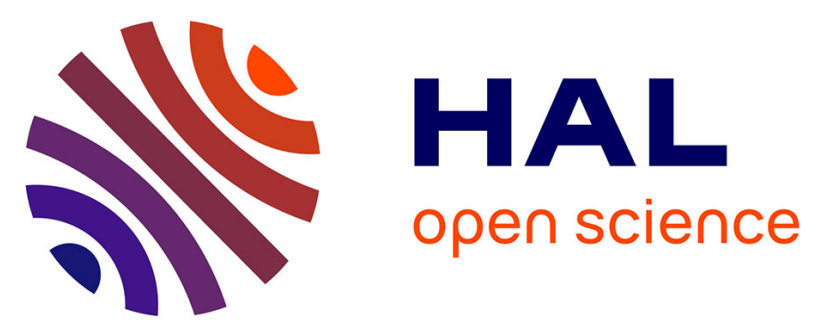

\title{
Development of a Swine Model of Left Bundle Branch Block for Experimental Studies of Cardiac Resynchronization Therapy
}

Montserrat Rigol, Núria Solanes, Juan Fernández-Armenta, Etelvino Silva, Adelina Doltra, Nicolas Duchateau, Aina Barcelo, Luigi Gabrielli, Bart

Bijnens, Antonio Berruezo, et al.

\section{To cite this version:}

Montserrat Rigol, Núria Solanes, Juan Fernández-Armenta, Etelvino Silva, Adelina Doltra, et al.. Development of a Swine Model of Left Bundle Branch Block for Experimental Studies of Cardiac Resynchronization Therapy. Journal of Cardiovascular Translational Research, 2013, 6 (4), pp.616622. 10.1007/s12265-013-9464-1 . hal-02282415

\section{HAL Id: hal-02282415 https://hal.science/hal-02282415}

Submitted on 16 Oct 2019

HAL is a multi-disciplinary open access archive for the deposit and dissemination of scientific research documents, whether they are published or not. The documents may come from teaching and research institutions in France or abroad, or from public or private research centers.
L'archive ouverte pluridisciplinaire HAL, est destinée au dépôt et à la diffusion de documents scientifiques de niveau recherche, publiés ou non, émanant des établissements d'enseignement et de recherche français ou étrangers, des laboratoires publics ou privés. 


\section{DEVELOPMENT OF A SWINE MODEL OF LEFT BUNDLE BRANCH BLOCK FOR EXPERIMENTAL STUDIES OF CARDIAC RESYNCHRONIZATION THERAPY}

Montserrat Rigol*1, DVM, PhD; Núria Solanes*1, DVM, PhD; Juan FernandezArmenta, MD; Etelvino Silva PhD; Adelina Doltra MD; Nicolas Duchateau, PhD; Aina Barcelo2, M.Sc.Eng; Luigi Gabrielli1,3, MD; Bart Bijnens4, PhD; Antonio Berruezo, MD, PhD; Josep Brugada, MD, PhD; Marta Sitges, MD, PhD.

*Both authors have equally contributed equally to this study.

${ }^{1}$ Cardiology Department. Institut d'Investigacions Biomèdiques August Pi i Sunyer (IDIBAPS), Hospital Clínic de Barcelona, Universitat de Barcelona (UB), Barcelona, Spain.

2 Sorin Group. Barcelona, Spain.

${ }^{3}$ Pontifica Universidad Católica de Chile.

${ }^{4}$ ICREA - Universitat Pompeu Fabra, Barcelona, Spain.

\section{Correspondence to:}

Montserrat Rigol.

Department of Cardiology. Institut Clínic del Tòrax. Hospital Clínic de Barcelona. Villarroel, 170. 08036 BARCELONA. Spain.

Tel: 34-93-227 5400 , ext. 3041.

FAX: 34-93-451 4148.

e-mail: mrigol@clinic.ub.es. 


\section{ABSTRACT}

Animal models that mimic human electrical and mechanical dyssynchrony often associated with chronic heart failure would provide an essential tool to investigate factors influencing response to cardiac resynchronization therapy. A standardized closed-chest porcine model of left bundle branch block (LBBB) was developed using 16 pigs. Radiofrequency applications were performed to induce LBBB, which was confirmed by QRS widening, a surface ECG pattern concordant with LBBB, and a prolonged activation time from endocardial. Echocardiography confirmed abnormal motion of the septum, which was not present at the baseline echocardiogram. High susceptibility of pigs to ventricular fibrillation during the endocardial ablation was overcome applying high-rate pacing during radiofrequency applications.

This is the first study to devise a closed-chest porcine model of LBBB that closely reproduces abnormalities found in patients with electrical and mechanical cardiac dyssynchrony, and provides a useful tool to investigate the basic mechanisms underlying cardiac resynchronization therapy benefits in heart failure.

\section{KEYWORDS}

Experimental study, porcine model, left bundle branch block, cardiac resynchronization therapy, cardiac dyssynchrony. 


\section{INTRODUCTION}

Several randomized studies involving thousands of patients with chronic heart failure have shown the beneficial effects of cardiac resynchronization therapy (CRT) [1] but the basic mechanisms underlying this benefit are scarcely known. Therefore, development of new animal models that mimic human electrical and mechanical dyssynchrony would provide a powerful tool to understand and investigate factors influencing response to CRT.

Currently, pigs, dogs and sheep are large animals commonly used in cardiovascular research [2-6] because of their similarity to the human anatomy and pathophysiology as well as their size, all of which allow for surgical and diagnostic procedures otherwise more difficult in smaller species [7]. Although the experience using animal models to study CRT is limited due to high cost and difficulty in developing a large animal model, the canine species is most often used [8-11]. Dogs have a cardiac conduction system with a distribution of Purkinje fibers very similar to humans [6] but this is a very expensive model. In contrast, the porcine model is cheaper and much easier for facilities to work with. However, a difficulty in working with pigs is that they are very susceptible to intractable ventricular fibrillation even with slight cardiac manipulation. To date only one study has developed an open-chest porcine model of left bundle branch block (LBBB) to evaluate the effect of nonexcitatory stimulus on left ventricular function [12] and to our knowledge no studies have standardized a closed-chest porcine model of LBBB. A closed-chest porcine model of electrical cardiac dyssynchrony would be a much more translational animal model and the results have a much higher potential to be extrapolated to clinical practice. 
Therefore, the aim of the present research was to standardize a novel closed-chest swine model of electrical cardiac dyssynchrony that mimics human electrical and mechanical activations for future studies of CRT and conduction abnormalities.

\section{MATERIALS AND METHODS}

Animal handling was approved by our Institutional Review Board and Ethics Committee (approval reference number: DMAH 5648). The management of the 16 Landrace $\mathrm{x}$ Large White pigs used in this study conforms to the Guide for the Care and Use of Laboratory Animals published by the United States National Institutes of Health (Eighth Edition. Washington, DC: The National Academies Press, 2011).

\section{Study design}

Animals were sequentially allocated into three groups; groups 1 and 2 were used for the standardization of the method to induce LBBB: Group $1(\mathrm{n}=3)$ : Radiofrequency applications with a power of 40-50 watts and a duration of 40-70 seconds were performed to induce a LBBB without pacing during the radiofrequency applications.

Group $2(\mathrm{n}=3)$ : Radiofrequency applications with a power of 25 watts and a duration of 30 seconds were performed to induce a LBBB without pacing during the radiofrequency applications. Group $3(\mathrm{n}=10)$ : LBBB induction using the standardized ablation method ( 25 watts and 30 seconds) and high rate pacing (160 beats/minute) during radiofrequency applications. Animal preparation

Sixteen $(33 \pm 3 \mathrm{~kg})$ animals were pre-medicated with an intramuscular cocktail of 3 $\mathrm{mg} / \mathrm{kg}$ ketamine (Imalgène $1000 \AA$, Merial, Lyon, France), $2.5 \mathrm{mg} / \mathrm{kg}$ xylazine 
(Rompun®, Bayer HealthCare, Kiel, Germany) and $0.17 \mathrm{mg} / \mathrm{kg}$ midazolam (Midazolam Sala $E F G \circledR$, Laboratorio Reig Jofre S.A., Barcelona, Spain). Anaesthesia was induced with intravenous (1-2 mg/kg) propofol (Propofol-Lipuro 1\%®, B. Braun Melsungen AG, Melsungen, Germany) and, after endotracheal intubation, maintained with continuous infusion $\left(10 \mathrm{mg} / \mathrm{kg} / \mathrm{h}\right.$ ) of propofol (Propofol Hospira $20 \mathrm{mg} / \mathrm{ml}{ }^{\circledR}$, Hospira Productos

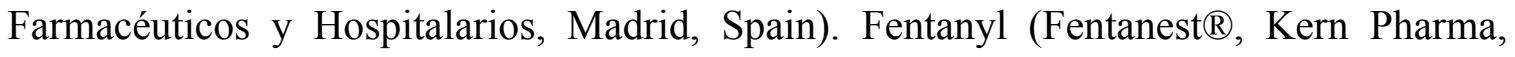
Germany) was used intravenously as an analgesic $(0.15-0.3 \mathrm{mg} / \mathrm{animal} / \mathrm{h})$.

One hour prior to introduction of the catheters, a continuous infusion of intravenous (5$10 \mathrm{mg} / \mathrm{kg} / \mathrm{h}$ ) lidocaine (Lidocaína ${ }^{\circledR}$ 0.4\%, B. Braun Medical SA, Rubí, Spain) was administered as an antiarrhythmic. An intravenous bolus of lidocaine (Lidocaína ${ }^{\circledR}$ 2\%, B. Braun) $(1 \mathrm{mg} / \mathrm{kg})$ was administered just before catheter manipulation.

Anticoagulant doses of unfractionated heparin (Hospira Productos Farmacéuticos y Hospitalarios) were given intravenously, $5000 \mathrm{U}$ as a bolus at the beginning of catheter manipulation followed by $1000 \mathrm{U} / 30$ minutes until the end of the surgery. Animals were monitored using a continuous electrocardiogram (ECG) registration, invasive arterial blood pressure (left femoral artery) and arterial blood gas.

\section{Closed-chest surgical procedure}

The right femoral artery was dissected and cannulated with an $8 \mathrm{~F}$ sheath to introduce a 3.5- mm tip catheter (Thermo-Cool Navi-Star, Biosense Webster Inc, Diamond Bar, CA, USA) and perform a voltage endocardial map of the left ventricle (LV) using an electroanatomic mapping system (Carto 3, Biosense Webster Inc). Then, using the same catheter and system, an epicardial map of the LV and right ventricle (RV) was performed. 
For this purpose, percutaneous pericardial access was obtained by a transthoracic subxiphoid puncture. The puncture was performed under fluoroscopic guidance using a Thuoy-type needle. Contrast medium was injected to confirm the position of the needle tip. A 0.32 guidewire was inserted into the pericardial space and a $9 \mathrm{~F}$ sheath was placed. A CRT device was implanted in our animal model to later study the effects of CRT. A bipolar RV lead with active fixation, model Beflex RF45 (Sorin Group, Barcelona, Spain) was implanted under fluoroscopic guidance, through a 9F sheath located on the right external jugular vein. One lead was inserted into the RV apex. After extending the lead screw, the standard parameters were checked for normal range ( $\mathrm{R}$ wave $>5 \mathrm{mV}$; impedance between 300 and $1000 \Omega$; threshold $<2 \mathrm{~V}$ at $0.4 \mathrm{~ms}$ ). The LV lead was implanted using 2 different approaches, according to the animal's anatomy. When the anatomy of the coronary sinus allowed positioning of an endocardial LV lead into a lateral coronary vein, a 9F sheath was used to advance a guiding catheter through the left external jugular vein into the right atrium. When the guiding catheter was inserted into the coronary sinus, a contrast injection allowed visualization of the coronary veins. A straight bipolar LV lead Situs OTW (Sorin Group) was then introduced over an angioplasty guidewire of $0.014 \mathrm{~mm}$. The LV lead was then positioned and fixed into the target vein (Fig. 1a). When the anatomy of the coronary veins did not allow placement of the LV lead, we implanted an active fixation lead in a lateral or anterolateral position of the LV epicardial surface via subxiphoid percutaneous access. To facilitate the second subxiphoid puncture, $60 \mathrm{ml}$ of physiologic serum were injected into pericardial space through the $9 \mathrm{~F}$ sheath positioned in the pericardial space to perform epicardial mapping (Fig. 1b). The $60 \mathrm{ml}$ of serum were removed immediately after the introduction of the 
second 9F sheath. In both procedures, LV lead parameters were within the expected range ( $\mathrm{R}$ wave $>5 \mathrm{mV}$; impedance between 300 and $1500 \Omega$; threshold $<5 \mathrm{~V}$ at $1 \mathrm{~ms}$ ), the pacing vector was programmed as bipolar or monopolar according to restrictions and phrenic stimulation was minimized though not always eliminated.

An external temporal pacemaker model PSA ERA 3000 (Biotronik, Madrid, Spain) was connected to the leads during the procedure, allowing different pacing configurations. Induction of LBBBLBBB was induced by radiofrequency ablation. Guided by endocardial electroanatomic mapping of the aortic root and under fluoroscopic guidance, the ablation catheter was advanced through the right femoral artery sheath and placed in the LV, below the aortic sigmoid valves. The left bundle branch potential was detected by a sharp spike preceding $(<35 \mathrm{~ms})$ the Q-wave of the intra-cardiac ECG. Several radiofrequency applications were delivered to achieve a change in QRS morphology and an increase of 50\% in QRS width compared with baseline.

In animals from group 3, high-rate pacing (160 beats/minute) was applied during radiofrequency applications in order to reduce the number of ventricular fibrillations during this procedure. High-rate pacing was performed using the bipolar RV lead from the CRT system already implanted. The pacemaker was programmed with asynchronous pacing (V00) from the RV apex and output of $10 \mathrm{~V}$ with $0.4 \mathrm{~ms}$ pulse width.

\section{Measurements}

To demonstrate the validity of the model to induce electrical cardiac dyssynchrony, a continuous ECG was performed to measure heart rate, PQ interval and QRS duration and morphology at baseline and after LBBB induction. The increase in QRS duration was 
quantified as percentage of increase in comparison to baseline as follows: (QRS duration after LBBB - Baseline QRS duration / Baseline QRS duration) x 100.

Moreover, endo- and epicardial electroanatomic maps were performed at baseline and after LBBB induction to analyze the electrical activation time of the LV. The increment of the activation time was calculated as the percentage of activated area within the first $10 \mathrm{~ms}$.

Epicardial echocardiography using a transesophageal probe (model 6Tc-RS, GE Healthcare, Milwaukee, Wisconsin, USA) inserted through a small subxiphoid incision was obtained before and after LBBB. Two-dimensional echocardiographic short-axis views of the LV were obtained at the base, midventricular and apical level in order to evaluate LV segmental and global systolic motion.

Percentage of ventricular fibrillation events during ablation was calculated as follows: (number of ventricular fibrillations during ablation / number of radiofrequency applications) x 100.

\section{Post-mortem analysis}

Animals were euthanized with an intravenous overdose $(70 \mathrm{mg} / \mathrm{kg})$ of sodium thiopental (Tiobarbital ${ }^{\circledR}$, B. Braun Medical Ltd, Sheffield, UK). In the first six animals (groups 1 and 2), hearts were harvested and LV was dissected to visualize and record the location of all ablation lesions.

\section{Statistical analysis}

Quantitative variables are presented as mean $\pm \mathrm{SD}$ values and categorical variables as 
percentage (\%). Kolmogorov-Smirnov test was used to evaluate normal distribution. Student unpaired-samples t-test was used to compare variables between two groups. Student paired- samples t-test was used to evaluate the changes in heart rate, PQ interval, QRS duration, and increment of electrical activation time compared with baseline values and each animal was used as its own control. A p value $<0.05$ was considered significant. Calculations were performed using the SPSS/PC statistical package (PASW statistics 18, SPSS Inc., Illinois, USA).

\section{RESULTS}

In animals from group 1, the mean number of radiofrequency applications was 12.3 \pm 7.6 with a power of $46.7 \pm 5.8$ watts and a duration of $56.7 \pm 15.3$ seconds per application. A complete atrioventricular block was induced in two out of three animals. In the other animal, LBBB induction was confirmed by QRS widening (from 51 to 100 ms). LBBB was successfully induced in all animals from group 2, which received 16.3 \pm 7.5 radiofrequency applications ( 25 watts; 30 seconds) and in nine out of 10 pigs from group 3, which received $7.8 \pm 6.2$ radiofrequency applications ( 25 watts; 30 seconds). One animal from group 3 was excluded from the analysis because a complete atrioventricular block was induced.

In animals from groups 2 and 3 together $(\mathrm{n}=12), \mathrm{LBBB}$ induction was confirmed by QRS widening that represented an increase of $79.3 \pm 23 \%$ of the baseline QRS width. A shift in ECG morphology and axis (pattern concordant with LBBB) was observed in all pigs. After the LBBB, PQ interval significantly increased from baseline; heart rate remained 
unchanged. Moreover, after LBBB electrical activation time was prolonged as compared to baseline in both endo- and epicardial electroanatomic mappings (Fig. 2) (Table 1).

In all animals, when LBBB was induced, echocardiography confirmed abnormal motion of the septum [13], which was not present at the baseline echocardiogram (Fig. 3). The lesions produced by radiofrequency applications in the endocardium of the LV of the animals from group 1 were deep and resulted in extensive ulcers at subvalvular location. However, in group 2 these lesions were less deep and more limited in diameter. Specifically, using a power of $46.7 \pm 5.8$ watts and a duration of $56.7 \pm 15.3$ seconds per application the lesions were too deep and extensive and two complete atrioventricular blocks of three attempts were induced; however, standardization of the radiofrequency applications to a power of 25 watts and 30 seconds of duration was sufficient to achieve LBBB in 12 of 13 animals, with moderate macroscopic lesions. (Fig. 4).In animals from group 3, high-rate pacing (160 beats/minute) was applied during radiofrequency applications, achieving a significantly lower percentage of ventricular fibrillations during ablation than in animals from group 2, to which pacing was not applied $(9.5 \pm 17.5 \%$ vs $39.8 \pm 8.9 \%$, respectively; $\mathrm{p}<0.05$ ).

The implantation of the CRT system was feasible in all animals $(n=16)$ despite the small body weight $(33 \pm 3 \mathrm{~kg})$. The LV lead was successfully implanted in a coronary vein in 10 out of 16 animals $(62.5 \%)$ and in the remaining $6(37.5 \%)$ using an epicardial subxiphoid access. Moreover, a better stability was achieved when the anatomy of the coronary sinus allowed positioning of the LV lead in a coronary vein. 


\section{DISCUSSION}

To our knowledge, this is the first study to devise a closed-chest porcine model of LBBB using localized endocardial radiofrequency ablation that closely reproduces abnormalities found in patients with electrical and mechanical cardiac dyssynchrony. LBBB induction was confirmed by QRS widening, specific changes in the ECG pattern concordant with LBBB and prolongation of activation time. The high susceptibility of pigs to ventricular fibrillation during the endocardial ablation was overcome with application of high-rate pacing.

Our experimental model offers some new features and advantages to previous experimental studies. First, the novelty of our experimental model is the use of high-rate pacing during the LBBB induction. To our knowledge no study has used this method to reduce the rate of ventricular fibrillation. Previous experimental studies have demonstrated that prophylactic administration of antiarrhythmic drugs slightly reduces the ventricular fibrillation rate [5] but not to the extent needed for an effective ablation of the left bundle; in our study, we have found an effective method to overcome the high vulnerability of the pig's heart to ventricular fibrillation. Sinus bradycardia and premature ventricular beats during radiofrequency ablation facilitate short-long-short sequences that may precede ventricular fibrillation. Transient pacing at high rate during ablation can avoid pauses and homogenize ventricular repolarization. In fact, in the clinical setting, temporary pacing is often used for the treatment of recurrent polymorphic ventricular tachycardia [14]. In a murine model, where atrioventricular node ablation induces early depolarizations and triggered activity, rapid pacing has been shown to suppress them [15]. 
On the other hand, there is only one previous study of biventricular pacing in an openchest porcine model with LBBB but no closed-chest model has been reported [12]. However, open-chest experimental models alter cardiac mechanics, which is an important feature for studying the effects of CRT [16]. Our closed-chest experimental model also offers the advantage of being closer to the procedures performed in humans and, therefore, the results obtained using this experimental model could be further extrapolated to clinical practice. Other studies that have developed canine models of LBBB for CRT have in fact been performed in closed chest [17-18]. However, our group has focused on swine because it is much more cost-effective to work with this species and the necessary facilities are readily available.

Finally, the model described here has the important advantage of compatibility with other standardized and widely used experimental models such as the porcine model of chronic myocardial infarction [4]. In our experimental model, we initially tried to place the LV lead in the coronary sinus as done in clinical practice. However, some animals $(37.5 \%)$ did not have adequate coronary

veins where a lead could be steadily positioned. Consequently, we decided to implant the lead in the pericardial "virtual" cavity. The advantage of this last implantation is that it can be performed independently of the coronary anatomy; on the other hand, better stability is achieved when the lead is positioned in a coronary vein, which also avoids transthoracic subxiphoid puncture. Nonetheless, in a set of animals with a weight significantly greater than that of the animals of the present study (data not shown) we were able to position the LV lead in a coronary vein without any problem. There are no previous studies in this regard, but our results indicate that the use of animals of greater 
weight, despite requiring a more complicated handling, facilitates the positioning of the LV lead in the coronary sinus. Limitations

In the model described here, pigs were healthy, lacking the co-morbidities of patients with heart failure and ventricular dysfunction. Moreover, the dyssynchrony resulting from the localized lesions induced in our model could be, in fact, different from that observed in patients with diffuse disease of the infrahisian-Purkinje system. Nevertheless, our animal model has many features of cardiac dyssynchrony in common with patients with LBBB.

The breed of swine used in our study has a higher growth rate compared to other breeds such as the Göttingen minipig. In fact, this higher growth rate would be a limitation of our model if used for longer-term studies. However, an advantage of using Landrace $\mathrm{x}$ Large White breed is the much less expensive cost as compared to minipigs.

\section{CONCLUSIONS}

Untreatable ventricular fibrillation during endocardial ablation has hampered the viability of the pig as a model of cardiac dyssynchrony, namely left bundle branch block. This drawback has been overcome by this novel closed-chest swine model of electrical dyssynchrony by inducing LBBB with radiofrequency ablation and applying high rate pacing to avoid ventricular fibrilation. The main advantage of this experimental model is that it is feasible, closely mimics human electrical and mechanical dyssynchrony, and provides a useful tool to investigate the basic mechanisms underlying CRT benefits in heart failure. 
Preprint version accepted to appear in Journal of Cardiovascular Translational Research.

Final version of this paper available at http://link.springer.com/article/10.1007\%2Fs12265-0139464-1 


\section{ACKNOWLEDGMENTS}

The authors are grateful to the Universitat de Barcelona facilities, Neus Portella (Hospital Clínic, Barcelona, Spain) for assistance, and Elaine Lilly, Ph.D. for English editing. They also acknowledge David Andreu (Hospital Clínic, Barcelona, Spain) and Daniel Traver (Biosense Webster, Barcelona, Spain) for their support on the electroanatomic mapping and ablation devices.

Funding: This study was supported in part by grants from the CENIT program of the Centro de Desarrollo Tecnológico Industrial (cvREMOD project; CEN-20091044), and the Spanish Government, REDINSCOR RD06/0003/0008. A Doltra received a personal grant from Fundació Clinic. 


\section{REFERENCES}

1. Cleland JG, Daubert JC, Erdmann E, Freemantle N, Gras D, Kappenberger L, Tavazzi

L (2005) The effect of cardiac resynchronization on morbidity and mortality in heart failure. N Engl J Med 352(15):1539-1549 2. Solanes N, Rigol M, Khabiri E, Castellà M, Ramírez J, Roqué M, Agustí E, Roig E, Pérez-Villa F, Segalés J, Pomar JL, Engel P, Massaguer A, Martorell J, Rodríguez JA, Sanz G, Heras M (2005) Effects of cryopreservation on the immunogenicity of porcine arterial allografts in early stages of transplant vasculopathy. Cryobiology 5:1130-1141

3. Rigol M, Solanes N, Sionis A, Gálvez C, Martorell J, Rojo I, Brunet M, Ramírez J, Roqué M, Roig E, Pérez-Villa F, Barquín L, Pomar JL, Sanz G, Heras M (2008) Effects of Cyclosporine, Tacrolimus and Sirolimus on Vascular Changes Related to Immune Response. J Heart Lung Transplant 27:416-422

4. Rigol M, Solanes N, Farré J, Roura S, Roqué M, Berruezo A, Bellera N, Novensà L, Tamborero D, Prat-Vidal C, Huzman MA, Batlle M, Hoefsloot M, Sitges M, Ramírez J, Dantas AP, Merino A, Sanz G, Brugada J, Bayés-Genís A, Heras M (2010) Effects of Adipose Tissue-Derived Stem Cell Therapy After Myocardial Infarction: Impact of the Route of Administration. J Cardiac Fail 16:357-366

5. Shofti R, Zaretzki A, Cohen E, Engel A, Bar-El Y (2004) The sheep as a model for coronary artery bypass surgery. Laboratory Animals 38:149-157 6. Chorro FJ, SuchBelenguer L, López-Merino V (2009) Animal models of cardiovascular disease. Rev Esp Cardiol 62(1):69-84

7. Murry CE, Field LJ, Menasché P (2005) Cell-based cardiac repair: reflections at the 10- year point. Circulation 112(20):3174-3183 
8. van Deursen C, van Geldorp IE, Rademakers LM, van Hunnik A, Kuiper M, Klersy C, Auricchio A, Prinzen FW (2009) Left ventricular endocardial pacing improves resynchronization therapy in canine left bundle-branch hearts. Circ Arrhythm Electrophysio 2(5):580-587

9. Mills RW, Cornelussen RN, Mulligan LJ, Strik M, Rademakers LM, Skadsberg ND, van Hunnik A, Kuiper M, Lampert A, Delhaas T, Prinzen FW (2009) Left ventricular septal and left ventricular apical pacing chronically maintain cardiac contractile coordination, pump function and efficiency. Circ Arrhythm Electrophysio 2(5):571-579

10. Vernooy K, Verbeek XA, Peschar M, Crijns HJ, Arts T, Cornelussen RN, Prinzen FW (2005) Left bundle branch block induces ventricular remodelling and functional septal hypoperfusion. European Heart Journal 26:91-98 11. Kerckhoffs RCP, Lumens J, Vernooy K, Omens JH, Mulligan LJ, Delhaas T, Arts T, McCulloch AD, Prinzen FW (2008) Cardiac resynchronization: Insight from experimental and computational models. Prog Biophys Mol Biol 97(2-3):543-561

12. Marrouche NF, Pavia SV, Zhuang S et al. Nonexcitatory Stimulus Delivery Improves Left Ventricular Function in Hearts with Left Bundle Branch Block. J Cardiovasc Electrophysiol 2002;13:691-695. 13. Parsai C, Bijnens B, Sutherland GR, Kim YJ, Tabata T, Wallick D, Saad E, Abdul-Karim A, Schweikert R, Saliba W, Tchou P, Natale A (2009) Toward understanding response to cardiac resynchronization therapy: left ventricular dyssynchrony is only one of multiple mechanisms. Eur Heart J 30:940-949

14. Olgin JE, Zipes DP (2007) Specific Arrhythmias: Diagnosis and Treatment. In: Libby P, Bonow RO, Mann DL, Zipes DP (editors) Braunwald's Heart Disease: A Textbook of Cardiovascular Medicine, 8th edn. Saunders Elsevier, Philadelphia, chap 35. 
15. Thomas G, Gurung IS, Killeen MJ, Hakim P, Goddard CA, Mahaut-Smith MP, Colledge WH, Grace AA, Huang CL (2007) Effects of L-type Ca2+ channel antagonism on ventricular arrhythmogenesis in murine hearts containing a modification in the Scn5a gene modelling human long QT syndrome 3. J Physiol 578(Pt 1):85-97

16. Bordachar P, Grenz N, Jais P, Ritter P, Leclercq C, Morgan JM, Gras D, Yang P (2012) Left ventricular endocardial or triventricular pacing to optimize cardiac resynchronization therapy in a chronic canine model of ischemic heart failure. Am J Physiol Heart Circ Physiol 303(2):H207-215

17. Liu L, Tockman B, Girouard S, Pastore J, Walcott G, KenKnight B, Spinelli J (2002) Left ventricular resynchronization therapy in a canine model of left bundle branch block. Am J Physiol Heart Circ Physiol 282:H2238-2244 18. Vernooy K, Cornelussen RNM, Verbeek XA, Vanagt WY, van Hunnik A, Kuiper M, Arts T, Crijns HJ, Prinzen FW (2007) Cardiac resynchronization therapy cures dyssynchronopathy in canine left bundlebranch block hearts. European Heart Journal 28:2148-2155 


\section{FIGURE LEGENDS}

Fig. 1 Representative fluoroscopic images of CRT lead implantation. a) endocardial access (coronary vein) of LV lead. MAP $=$ Thermo-Cool Navi-Star (Biosense Webster Inc, Diamond Bar, CA, USA) catheter for performing endocardial mapping and ablation. The image shows the guidewire placed in the epicardial space to introduce the sheath, and the catheter to obtain the epicardial map. b) pericardial access of LV lead. ES = two epicardial sheaths, one for the epicardial mapping and one for the LV lead implantation

Fig. 2 The electrical activation pattern of the left ventricle before and after LBBB. Left: 6 lead ECG recording, which shows an increase in QRS width and a shift in ECG morphology and axis after LBBB. Right: Representative images of endocardial activation maps for the same animal illustrating a delay in the electrical activation of the LV lateral wall after LBBB

Fig. 3 M-mode echocardiography before (left) and after (right) left bundle branch ablation. An abnormal septal motion (arrows), consisting of a fast inward contraction and outward relaxation of the septum within the QRS width, is observed in the left image. In contrast, no abnormal septal motion can be seen before the ablation procedure

Fig. 4 Representative photographs of the ablation lesions. a) Detail of the dissected LV of one animal from group 2. The image shows the effective ablation lesions localized below the aortic sigmoid valves. b) Detail of the dissected RV of one animal from group 
Final version of this paper available at http://link.springer.com/article/10.1007\%2Fs12265-0139464-1

1. The image shows deep and extensive ulcers visualized in the RV, originating from the LV after the radiofrequency applications 
Final version of this paper available at http://link.springer.com/article/10.1007\%2Fs12265-0139464-1

Figure 1
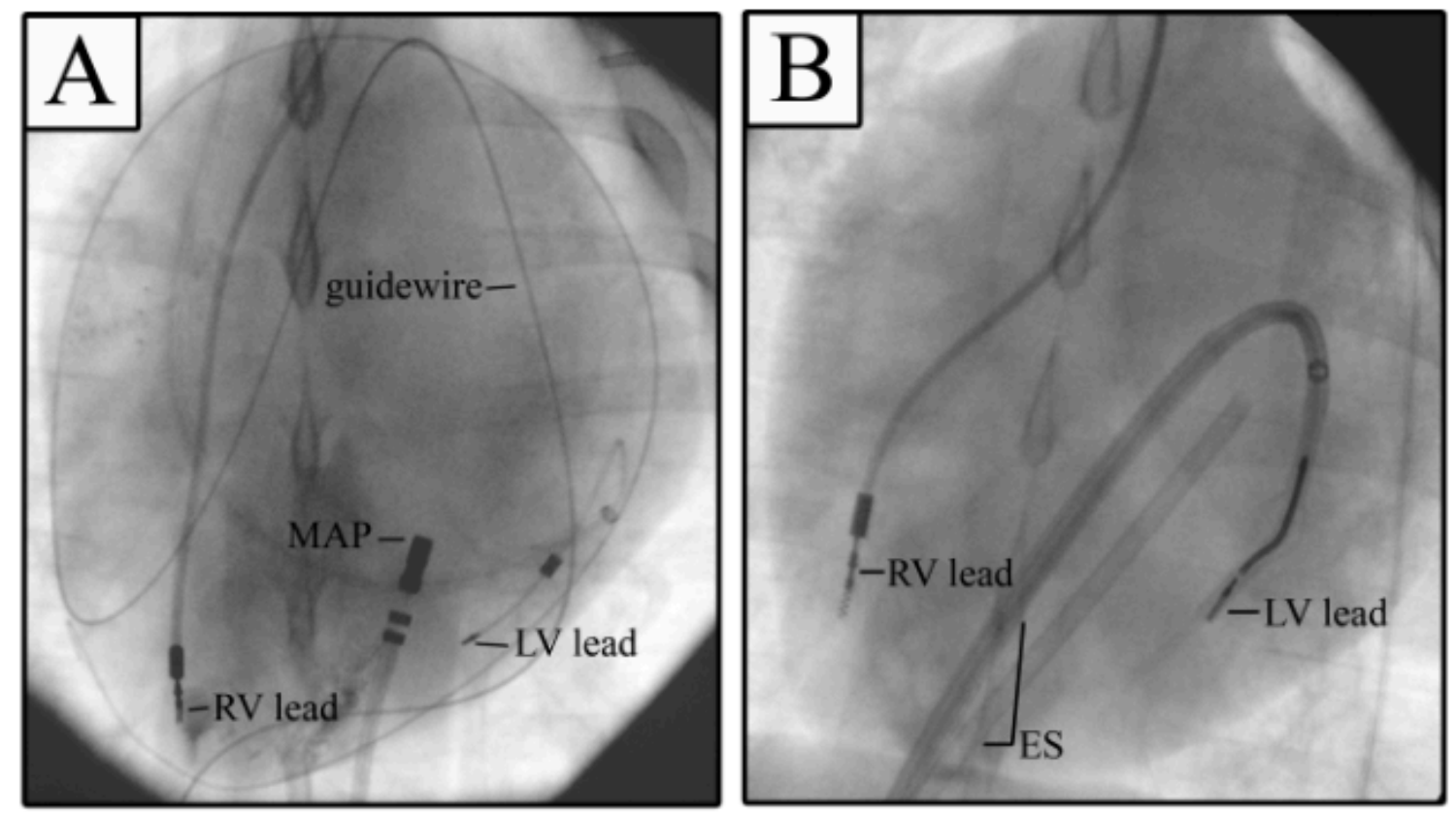

Figure 2 
Final version of this paper available at http://link.springer.com/article/10.1007\%2Fs12265-013-
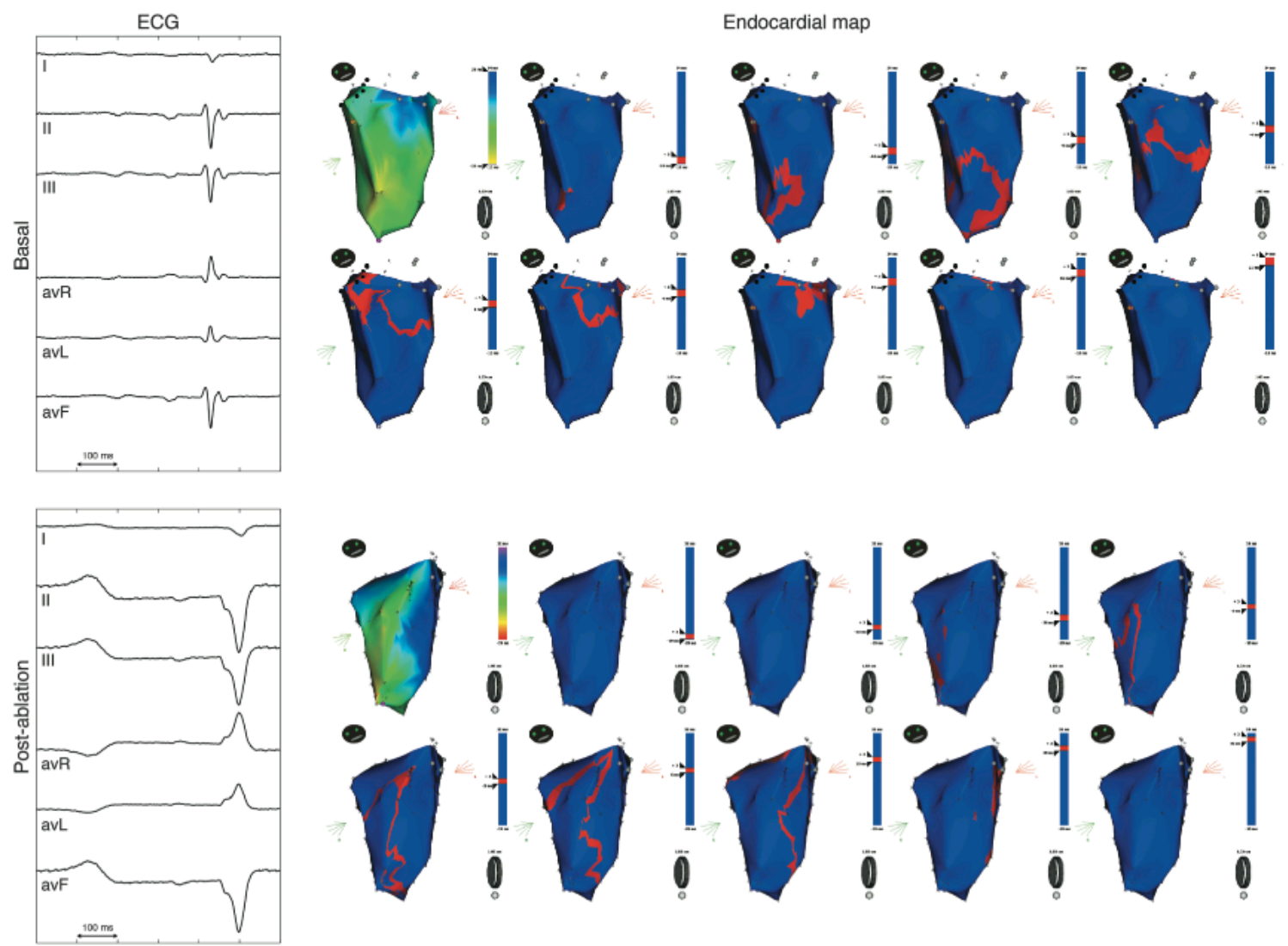

Figure 3
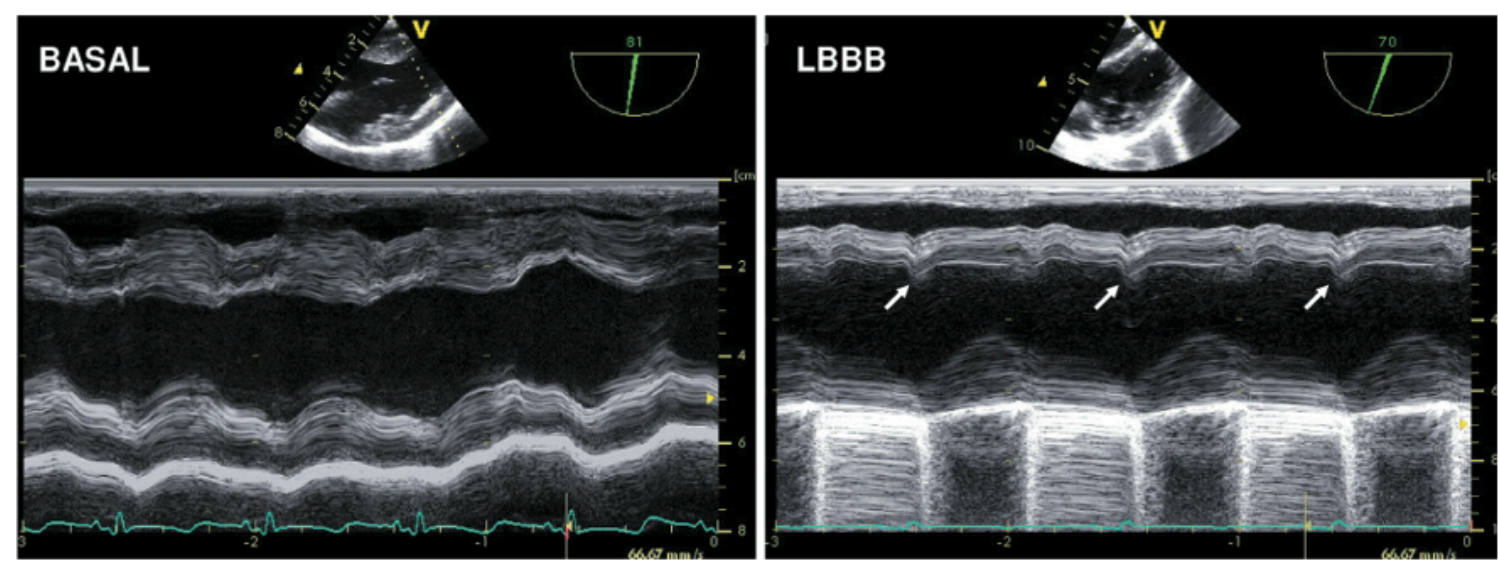

Figure 4 

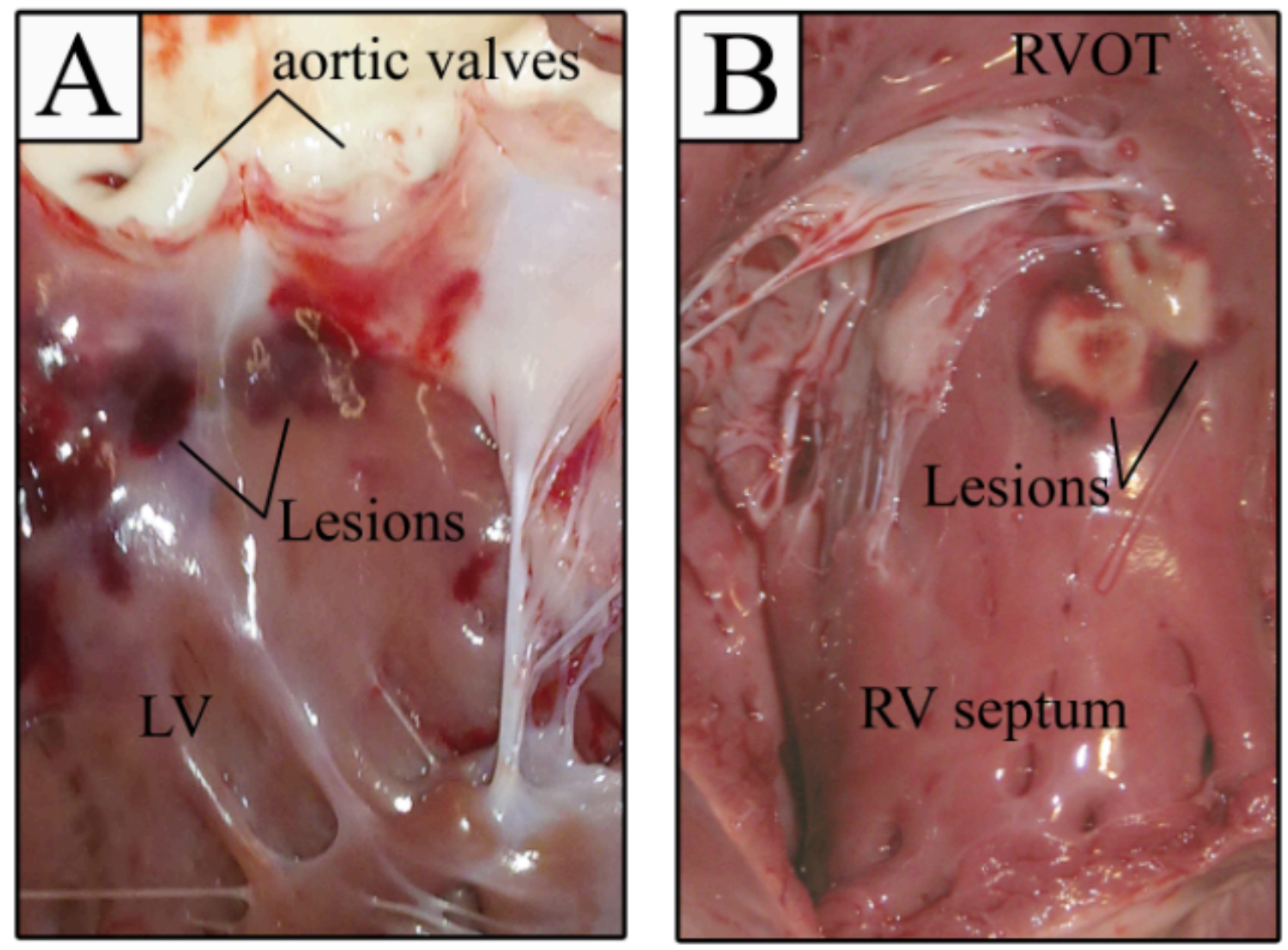


\section{TABLES}

Table 1. Electrophysiologic parameters before and after induction of LBBB, in animals from groups 2 and 3 together $(n=12)$.

Baseline (before LBBB)

After LBBB induction

Heart rate (bpm)

PQ interval (ms)

QRS duration (ms)

Activation time from

endocardial mapping (ms)

Activation time from

epicardial mapping (ms)
$84.7 \pm 16.3$

$109.5 \pm 22.9$

$50 \pm 4.4$

$40.7 \pm 8.4$

$69.7 \pm 22.8^{*}$

$82.2 \pm 18.5$

$118 \pm 20.3^{*}$

$89.7 \pm 14.4^{* *}$

$30.4 \pm 6.5$

$71.1 \pm 15.3^{*}$

Abnormal motion of the

$0 \%$

$100 \%$

${ }^{*} \mathrm{p}<0.05$ vs baseline

${ }^{* *} \mathrm{p}<0.001$ vs baseline 